\title{
Efeitos do gasto com a judicialização da saúde no orçamento da Secretaria Estadual de Saúde do Distrito Federal entre 2013 e 2017
}

\author{
Effects of spending on the Health's Judicialization in the budgetary of the State \\ Department of Health of the Federal District between 2013 and 2017
}

Efectos del gasto con la judicialización de la salud en lo presupuesto de la Secretaria de Estado de Salud del Distrito Federal entre 2013 y 2017

Resumo: Objetivo: Identificar os efeitos que o gasto com a judicialização da saúde provoca na execução orçamentária da Secretaria Estadual de Saúde do Distrito Federal entre 2013 e 2017. Metodologia: Trata-se de um estudo descritivo retrospectivo, com utilização da técnica de análise documental, com base nos dados de 3.545 processos judiciais contra a secretaria, requerendo acesso a medicamentos e procedimentos médicos. Resultados: O montante gasto foi de $\mathrm{R} \$ 122$ milhões de reais em valor corrente. A maior parcela de recursos foi para empenhar 607 processos $(17,1 \%)$ em $2017, R \$ 29,2$ milhões de reais $(23,9 \%)$. Do total de reinvindicações judiciais movidas, foram empenhadas $R \$ 87$ milhões de reais $(71,8 \%)$ da subfunção suporte profilático e terapêutico (303); 2.498 processos judiciais $(70,5 \%)$ relacionados ao fornecimento de medicamentos pelo SUS; 372 ações judiciais $(10,5 \%)$ reivindicando a prestação de serviços de internação compulsória; 271 ações judiciais pedindo órteses e próteses $(7,6 \%)$ e 157 ações judiciais requerendo exames e procedimentos $(4,4 \%)$. Conclusão: $O$ número de ações judiciais aumentou consideravelmente durante o período analisado. A judicialização apesar de ser um instrumento importante de garantia dos direitos dos cidadãos, reforça a iniquidade e provoca dificuldades na operação cotidiana das equipes que fazem a gestão do sistema de saúde. Ademais, contribui e tem efeito na execução orçamentária na secretaria, notadamente na assistência farmacêutica, inviabilizando em parte o cumprimento de ações e serviços de saúde previstas no Plano de Saúde além de impossibilitar uma eficiente aplicação dos recursos, que tem o seu acompanhamento e controle comprometido hoje pelo modus operandi adotado.

Palavras-chave: Gastos em Saúde. Judicialização da Saúde. Orçamentos. Economia da Saúde.

Abstract: Objective: To identify which are the health judicialization spending effects in the budgetary execution of the Federal District. Methodology: It is a retrospective descriptive study, using the documentary analysis technique. The database of this study are the 3,545

\footnotetext{
1 Mestre em Saúde Pública, Economista e especialista em Economia da Saúde e Finanças. Fundação Oswaldo Cruz em Brasília. E-mail: cassia.esaf@gmail.com.

2 Doutor Saúde Coletiva, Médico com Residência Médica em Medicina Preventiva e Social. Especialista em Políticas Públicas e Gestão Governamental (EPPGG), Ministério do Planejamento. E-mail: faustops@uol.com.br
} 
lawsuits moved between 2013 and 2017, against the secretary requiring access to medicines and medical procedures. Results: The amount spent was $R \$ 122$ million reais in current value. The largest portion of resources was used to commit 607 cases $(17,1 \%)$ in $207, R \$ 28,2$ million (23,9\%). Considering the entire number of moved lawsuits, $R \$ 87$ millions $(71,8 \%)$ of the prophylactic and therapeutic support subfunction were commited. Furthermore, 2498 lawsuits related with suppy of medicines of SUS $(70,5 \%)$ were commited, 372 Lawsuits (10,5\%) claiming the provision of compulsory hospitalization services; 231 lawsuits requesting ortheses and protheses (7,6\%) and 157 lawsuits requesting medical exam and procedures $(4,4 \%)$. Conclusion: The number of lawsuits has increased considerably. The Health's Judicialization still of being an important instrument to guarantee the rights of citizens, strengthens the iniquity and causes difficulties in the daily operation of teams that make the management of the health system. In addition, contributes and has an effect on the budgetary execution in the secretariat, especially in the pharmaceutical assistance, preventing in part the fulfillment of health services and actions laid down in the health plan in addition to make it impossible for an efficient use of resources, which has its monitoring and control committed today by the modus operandi adopted.

Keywords: Health Expenditures. Health's Judicialization. Budgets. Health Economics.

Resumen: Objetivo: Identificar los efectos que el gasto con la judicialización de la salud provoca en la ejecución de la Secretaria de Estado de Salud del Distrito Federal. Metodología: Se trata de un estudio descriptivo retrospectivo, con la utilización de la técnica de análisis documental, con base en los datos de 3.545 procesos judiciales contra la secretaría que se movieron entre 2013 y 2017, en los cuales se requería el acceso a medicamentos y a procedimientos médicos. Resultados: El importe gastado fue de $\mathrm{R} \$$ 122 millones de reales en valor corriente. La mayor parte de recursos fue para empeñar 607 procesos $(17,1 \%)$ en $2017, R \$ 29,2$ millones de reais $(23,9 \%)$. Del total de reinvindicaciones judiciales llevadas a cabo, fueron empeñados $R \$ 87$ millones de reais $(71,8 \%)$ de la subfunción soporte profiláctico y terapéutico (303); 2.498 procesos judiciales $(70,5 \%)$ relacionados con el suministro de medicinas por el SUS; 372 acciones judiciales $(10,5 \%)$ reivindicando la prestación de serviços de internación compulsoria; 271 acciones judiciales pidiendo órtesis y prótesis $(7,6 \%)$ y 157 acciones judiciales en las que se requerían exámenes y procedimientos (4,4\%). Conclusión: El número de demandas ha aumentado considerablemente. La Judicialización de la Salud a pesar de ser un instrumento importante para garantizar los derechos de los ciudadanos, fortalece la iniquidad y provoca dificultades en el funcionamiento cotidiano de los equipos que hacen que la gestión del sistema de salud. Además, contribuye y tiene un efecto sobre la ejecución presupuestaria de la Secretaría, especialmente en la asistencia farmacéutica, evitando en parte el cumplimiento de los servicios de salud y las acciones establecidas en el plan de salud, además de hacer lo imposible para un uso eficiente de los recursos, lo cual tiene su seguimiento y control comprometidos hoy por el modus operandi adoptado.

Palabras-Ilave: Gastos em Salud. Judicialización de la Salud. Presupuestos. Economía de la Salud.

\section{Introdução}

Cada vez mais os usuários do sistema de saúde reivindicam suas necessidades por 
intermédio da judicialização da saúde. Buscam "garantir a assistência à saúde com ação do Poder Judiciário, para assegurar o Direito à Saúde mediante a determinação do fornecimento de medicamentos, produtos e serviços de saúde para os cidadãos que recorrem à Justiça". (1)

De acordo com Barroso o "fenômeno da judicialização da saúde" proporcionou efeitos adversos aos tribunais e gestores (2). O número de processos aumenta consideravelmente a cada ano nos tribunais, comprometendo a atuação do órgão que poderá não possuir capital humano suficiente para atender a demanda e analisar as ações. No caso do gestor, a execução da decisão judicial comprometerá significativamente o orçamento da saúde.

O gasto em saúde "deve estar ligado ao planejamento, como instrumento que baliza o orçamento" e "nenhum gasto deverá ser realizado sem que haja disponibilidade de recursos orçamentários financeiros", consoante Mendes (3). Ou seja, o gestor deverá ser prudente na execução dos recursos orçamentários e financeiros, contemplando somente o que foi estabelecido no planejamento.

A Constituição Federal de 1988, no art. 165, determina como instrumentos de planejamento do país o Plano Plurianual (PPA), a Lei de Diretrizes Orçamentárias (LDO) e Lei Orçamentária Anual (LOA) (4). No caso da área da saúde, os instrumentos de planejamento são: o Plano Estadual de Saúde (PES), a Programação Anual de Saúde (PAS) e Relatórios de Gestão (Relatórios Detalhado do Quadrimestre Anterior - RDQA e Relatório Anual de Gestão - RAG).

O Ministério da Saúde (MS), as Secretarias Estaduais e Municipais de Saúde elaboram o seu Plano de Saúde em consonância com a programação da política de saúde e o gestor deve estar atento às fases da execução orçamentária e ao cumprimento das metas constantes no plano de saúde. Essa é uma situação preocupante considerando a restrição de recurso público e gastos com a judicialização, que podem impactar no orçamento previsto, interferir na execução de ações e políticas de saúde, além de gerar gastos elevados (5).

Vários estudos realizados constataram que ações poderiam ter sido evitadas ou que geraram gastos elevados e não previstos comprometendo de alguma forma a saúde (6) (7). A judicialização da política de assistência farmacêutica no Distrito Federal começou com as ações por medicamentos antirretrovirais, impetradas por pacientes com AIDS contra o SUS (8). 
Em estudo recente realizado pelo Tribunal de Contas da União (9) foi constatado que os gastos da União com processos judiciais referentes à saúde em 2015 foram de $R \$ 1$ bilhão, um aumento de $1.300 \%$ no período de 7 anos. De acordo com a pesquisa, a concentração de ações judicias está nos Estados, se considerado a quantidade. Pode-se inferir que a judicialização em saúde tornou-se um importante instrumento para a sociedade requerer os seus direitos nos últimos anos.

Este processo é crescente e tem provocado desorganização nos sistemas de planejamento e finanças dos entes federados em virtude da imprevisibilidade das ações e dos custos delas decorrentes. Neste sentido, o artigo objetivou-se identificar os efeitos do gasto com a judicialização da saúde na execução do orçamento da Secretaria Estadual de Saúde do Distrito Federal entre 2013 e 2017. Não foi encontrado estudos sobre o Distrito Federal com esse enfoque, revelando um caráter inédito da pesquisa. Ainda, foi definido esse território considerando a sua peculiaridade por ser um ente da federação que acumula tanto atribuições de estado quanto de município.

\section{A Judicialização da saúde}

O artigo 196 da Constituição Federal (CF) estabeleceu a saúde como direito de todos e dever do Estado, devendo ser "garantido mediante políticas sociais e econômicas que visem à redução do risco de doença e de outros agravos e ao acesso universal e igualitário às ações de serviços para sua promoção, proteção e recuperação" (4).

Por questões de ordem econômica, política e de mau funcionamento dos serviços de saúde, o SUS ainda não conseguiu concretizar o preceito do atendimento integral previsto na CF. Os usuários tem recorrido ao Poder Judiciário como solução para o acesso a medicamentos de alto custo, diagnósticos, internações ou procedimentos. Esse ato, conjuntamente com a requisição de procedimentos e medicamentos não fornecidos pelo SUS, é conhecido por todos como o fenômeno da judicialização da saúde.

A judicialização da saúde é hoje um dos temas mais estudados pela academia e pelos juristas. Há dez anos Andrade et al (10) já sinalizavam sobre a sua complexidade

A complexidade do fenômeno, por suscitar a interface entre esferas do Poder Público - Judiciário e Executivo -, confrontados no desafio constitucional de garantir os direitos universais dos cidadãos à atenção integral à saúde, repercute no constrangimento dos gestores de saúde pública frente aos mecanismos jurídicos que visam a garantir aos pacientes/usuários a assistência médica recomendada. Tais constrangimentos ultrapassam os conflitos os conflitos relacionados à 
alocação de recursos limitados, culminando, em alguns casos, em processos criminais envolvendo os responsáveis pela gestão do sistema de saúde.

Se, por um lado, as decisões judiciais visam a garantir o atendimento ao direito e às necessidades do cidadão, por outro remetem ao gestor a responsabilidade da decisão de alocação de recursos que muitas vezes contradita o princípio da equidade de saúde.

Dallari (11) corrobora com essa perspectiva quando apresenta aspectos particulares do tema em um artigo. A autora diz que dispor de meios adequados que asseguram a realização dos "direitos declarados exige importantes adaptações nos modos de interpretar a legitimidade das normas, tanto em sua origem quanto em sua aplicação".

As primeiras ações judiciais impetradas contra o SUS ocorreram nos anos noventa, quando pacientes portadores do vírus HIV demandaram o fornecimento de antirretrovirais (8). Para Romero, após 2001, as ações movidas contra o SUS cresceram substancialmente, assim como a variedade de medicamentos solicitados incluindo aqueles para atenção básica e para média complexidade. Segundo o autor, a política de assistência farmacêutica foi profundamente prejudicada por esse acontecimento, uma vez que ocorreu remanejamento de recursos e limitação da adoção de processos técnicos.

Com o tema em destaque e a ocorrência de mais demandas, outras pesquisas foram desenvolvidas. Em um estudo realizado sobre as distorções causadas por ações judiciais movidas contra a Secretaria Municipal da Saúde de São Paulo, Vieira e Zuchhi constataram que ações judiciais por medicamentos poderiam ter sido evitadas se fossem consideradas as diretrizes do Sistema Único de Saúde, a organização do atendimento em oncologia e a observância das relações de medicamentos essenciais (6). Verificou-se que decisões como essa comprometem a equidade no acesso e o uso racional de medicamentos, conforme orienta a Política Nacional de Medicamentos (PNM) (12).

A Assistência Farmacêutica representa hoje um dos setores que causa maior impacto financeiro no orçamento das Secretarias Estaduais de Saúde (SES). Delduque e Marques constataram em uma pesquisa sobre a judicialização da política de assistência farmacêutica no Distrito Federal que os demandantes individuais solicitam, em sua maioria, medicamentos que estão fora das listas oficiais e protocolos clínicos (14). A ausência de um gerenciamento eficiente pode gerar grandes efeitos deletérios para sistema (13).

Nesta mesma linha de raciocínio, Diniz e Schwartz (8) consideram que a judicialização "traz consequências econômicas para a organização da política". As pesquisadoras indicaram "a ineficiência em relação à escala e a dificuldade de controle das 
quantidades consumidas e estocadas". O Ministério da Saúde passou a adquirir os medicamentos sem considerar o fato das ações judiciais serem instauradas a qualquer momento, priorizando exclusivamente a garantia de melhores preços.

O conflito de interesses pelo direito à saúde tornou-se um caminho eletivo de acesso à saúde com sinais de disputa entre autores dos setores privado e público na prática da judicialização da saúde. Há hoje um imenso mercado de medicamentos sem supervisão regulatória adequada, que visam prescrições médicas como modo de fortalecer o a indústria farmacêutica (15).

Neto et al (16) chegou a mesma constatação ao conhecer a percepção dos médicos prescritores em Minas Gerais. Os autores notaram que as indústrias têm utilizado meios para convencer pacientes e/ou médicos do uso de medicamentos ou equipamentos não padronizados no SUS. Uma das estratégias das indústrias farmacêuticas é apoiar experiências comunitárias que reúnem crianças e jovens portadores de diabetes com objetivo de introduzir bombas de insulina.

Para Diniz et al (8), a judicialização resume a política de saúde à dispensação do medicamento de alto custo. Os estudiosos apuraram que o governo brasileiro se sujeita a monopólios de distribuição de medicamentos e dificultam a compra planejada de medicamentos para pacientes com mucopolissacaridose (MPS), por exemplo. Neto et al (16), analisou 2.412 processos em Minas Gerais e constatou que poderia existir uma aliança entre profissionais da medicina e do judiciário e beneficiando o mercado farmacêutico.

No caso de tratamento de doenças raras, Sartori Junior et al (17) anunciaram, à época, que esta situação decorria da ausência de uma política que padronize o acesso aos tratamentos para pacientes com doenças raras. As decisões tomadas pelo Judiciário no julgamento trazem, a curto e médio prazos, efeitos sistêmicos para o SUS, que oneram o serviço público e interferem na política pública

Embora a judicialização da saúde garanta o acesso a milhares de usuários, essa também gera realidades sociomédicas extremamente difíceis, além de desafios administrativos e fiscais que têm o potencial de aumentar as desigualdades na prestação de serviço de saúde (18). Apesar de compreenderem que é um direito dos usuários, os profissionais de saúde não são simpáticos às sentenças judiciais, de acordo com Ramos e Gomes (19). Consideram esse ato injusto, uma vez que outras pessoas deixam de ser 
atendidas em função desta priorização, se tal situação é produto de uma ação ineficaz do Estado na execução da política de saúde (16).

Outro aspecto priorizado pelos autores é a efetivação do direito à saúde. Trevisan et al (20) constataram a violação do direito à saúde e interrupção do tratamento prestado pelo Estado a pacientes com PKU, no Rio Grande do Sul, levando-os a recorrerem aos tribunais. Cabe ressaltar que, em alguns casos, a reivindicação judicial seria importuna porque produtos e medicamentos já estariam contemplados na política de assistência farmacêutica nacional. A não concessão de algum produto ou prestação de serviço o usuário, estaria diretamente relacionada a falhas de gestão.

Acionar o Poder Judiciário pode proporcionar o exercício dos princípios constitucionais da universalidade, integralidade e equidade na assistência à saúde, contudo, por outro lado, traz efeito deletérios na interpretação de Andrade et al (10). Ao garantir o direito do requerente via processo judicial, pode transferir ao gestor público a responsabilidade de decisões administrativas que contradizem princípios constitucionais, como mencionado anteriormente.

Pode-se inferir que a judicialização em saúde tornou-se um importante instrumento para a sociedade requerer os seus direitos e ter a suas necessidades em saúde atendidas, como é o caso de pacientes portadores de doenças raras. Por outro lado, a judicialização também causa a instabilidade orçamentária, provocando distorções entre a alocação de recursos e o que havia sido planejado.

\section{Gestão de recursos públicos e do Sistema Único de Saúde}

Orçamento é instrumento de intervenção planejada do Estado para expressar, por um período de tempo, sua política de trabalho e plano de governo, contendo autorização legislativa para a arrecadação de receitas e realização das despesas. A Secretaria do Tesouro Nacional (STN) conceitua orçamento público como sendo a "Lei de iniciativa do Poder Executivo que estima a receita e fixa a despesa da administração pública. É elaborada em um exercício para depois de aprovada pelo Poder Legislativo, vigorar no exercício seguinte". (21)

Segundo o artigo 165 da Constituição Federal de 1988, o orçamento é materializado em três instrumentos de planejamento: o Plano Plurianual - PPA (estratégico), a Lei de Diretrizes Orçamentárias - LDO (tático) e Lei Orçamentária Anual - LOA (operacional) (4). 
O PPA tem como propósito de viabilizar a implementação e a gestão das políticas públicas, orientar a definição de prioridades e auxiliar na promoção do desenvolvimento sustentável, por meio de programas temáticos e de gestão, manutenção e serviços ao Estado. A sua vigência é de 4 anos, período não coincidente com o mandato presidencial, porém equivalente (22).

Instituída pela CF de 1988, a LDO é um instrumento de conexão entre o planejamento e orçamento (PPA e LOA) e viabilização da execução dos programas governamentais, conforme art. 165, inc. II, com vigência de 1 ano. Sua função é orientar a elaboração, aprovação e execução da LOA. A LOA é a lei responsável por executar os programas definidos no PPA e priorizados na LDO, mediante a arrecadação de receita e a realização de despesa (22).

O orçamento-programa é o atual modelo orçamentário do Brasil e tem como principal característica a vinculação do planejamento ao orçamento. O planejamento pode ser entendido como um processo de análise e decisão que precede, preside e segue a ação individual ou coletiva dos agentes na solução de problemas com eficácia e eficiência. Este tem como foco atingir plenamente os objetivos previamente determinados.

Ao elaborar um orçamento é imprescindível considerar que a capacidade do gasto depende fundamentalmente da capacidade de auferir receitas. A receita cumpre um papel importante no processo orçamentário, cuja previsão dimensiona a capacidade governamental em fixar a despesa e, no momento da sua arrecadação, torna-se instrumento condicionante na execução orçamentária da despesa (22). Quanto às despesas orçamentárias, estas são fixadas na LOA ou por conta de créditos especiais ou extraordinários e dependem de autorização legislativa (crédito) e da existência de recursos (financeiro).

De acordo com a Portaria MOG no 42, de 14 de abril de 1999 (23), as ações constantes nas leis orçamentárias passariam a ser identificadas em termos de função, subfunção, programa, ação (projeto, atividade ou operação especial) (quadro 1). Esta classificação começou a vigorar na União, Estados e Distrito Federal a partir do exercício financeiro de 2000, e nos Municípios, a partir do exercício financeiro de 2002. A função é o maior nível de agregação das diversas áreas de despesa que competem ao setor público e a subfunção representa uma partição da função, visando a agregar determinado subconjunto de despesa do setor publicado (22). 
As programações orçamentárias estão organizadas em programas de trabalho que contêm informações qualitativas e quantitativas (24). A implementação dos programas de trabalho ocorre por meio de um sistema de classificação estruturado. Essa classificação possibilita expressar não só "com o que" o governo gastava os recursos, mas também com que finalidade, ou "para que" eram empregados os esforços da administração pública. A programação orçamentária quantitativa determina a quantidade de bens e serviços a serem entregues, além de estimar o montante necessário para o desenvolvimento da ação orçamentária (24).

Segundo a Lei no 4.320/1964, a despesa orçamentária percorre três estágios: empenho, liquidação e pagamento. O empenho é o ato emanado de autoridade competente que cria para o Estado obrigação de pagamento pendente ou não de implementação de condição (25). É quando ocorre o comprometimento de parcela da dotação orçamentária, dentro do limite de crédito concedido na dotação orçamentária própria. Também é conhecida como uma garantia que se dá ao fornecedor ou prestador de serviços de que o fornecimento ou o serviço contratado será pago, desde que observadas as cláusulas contratuais. É materializada por meio da Nota de Empenho, que deduz dos recursos orçamentários a parcela correspondente da natureza da despesa (26).

A liquidação consiste no reconhecimento formal de que a despesa foi executada, e é a última etapa da execução orçamentária da despesa. Após essa etapa, resta executar a despesa sob o ponto de vista financeiro, ou seja, o pagamento que se concretiza quando o ordenador de despesa emite a ordem bancária a favor do credor (22).

Na área da saúde, o Plano de Saúde (PS) consolida o processo de planejamento em saúde. A periodicidade de elaboração do plano é a cada quatro anos, sendo revisto a cada ano em função de novas metas de gestão e adequação à dinâmica da política de saúde. $\mathrm{O}$ funcionamento do sistema de planejamento em nível das três esferas de governo se apresenta com a formulação e/ou revisão periódica dos instrumentos: o Plano de Saúde (PS) e suas respectivas Programações Anuais de Saúde (PAS), instrumento que operacionaliza as intenções expressas no PS, e o Relatório de Gestão (RG), instrumento que apresenta os resultados alcançados e orienta eventuais redirecionamentos que se fizerem necessários (26).

Os recursos federais, estaduais e municipais destinados ao SUS devem ser indicados e seus valores apresentados no PPA, na LDO e na LOA, segundo os programas definidos 
no Plano de Saúde (PS) e na Programação Anual de Saúde (PAS). É importante destacar que todos os entes governamentais devem elaborar os instrumentos do processo orçamentário, conforme determinação da Constituição. E o Plano de Saúde (PS) deve corresponder ao PPA, isto é, ele constitui a parte que trata da área da saúde no PPA do governo. Já a Programação Anual de Saúde (PAS) deve corresponder à LDO - anual -; e, também, à LOA (anual). Todos estes instrumentos funcionam e se relacionam por meio de um ciclo composto pelas etapas do planejamento, do orçamento, da execução orçamentária, do acompanhamento, do controle público e da avaliação dos recursos aplicados em saúde.

De acordo com Mendes "o gasto em saúde deve estar ligado ao planejamento, como instrumento que baliza o orçamento" e "nenhum gasto deverá ser realizado sem que haja disponibilidade de recursos orçamentários financeiros" (3). Isso significa dizer que o gestor deverá ser prudente na execução dos recursos orçamentário e financeiro, contemplando somente o que foi estabelecido no planejamento.

A execução do gasto em saúde é realizada por intermédio do Fundo de Saúde (FS). A Constituição Federal e as legislações federais da área da saúde determinam a existência de um Fundo de Saúde, enquanto Conta Especial, em que são depositados e movimentados os recursos financeiros do sistema sob a fiscalização do Conselho de Saúde (artigo 33 da Lei 8.080/90) e incisos I e V do artigo 4ํ da Lei 8.142/90) (27) (28).

A Lei n. 141/2012 determina que o FS seja uma Unidade orçamentária e gestora dos recursos das ações e serviços públicos de saúde (29). Unidade orçamentária "é um segmento da administração direta a que o orçamento consigna dotações específicas para a realização de seus programas de trabalho e sobre os quais exerce o poder de disposição".

Quanto ao acompanhamento e controle do fundo, esses são realizados por ampla divulgação de documentos. O Sistema de Informações de Orçamentos Públicos em Saúde (SIOPS) reúne informações para apurar as receitas e as despesas públicas com saúde; o Relatório Resumido de Execução Orçamentária (RREO) que afere a aplicação do limite mínimo estabelecido no $\S 3^{\circ}$ do art. 198 da Constituição Federal, incluído pela Emenda Constitucional (EC) nº 29/2000, regulamentada pela Lei Complementar (LC) nำ141/2012 (29). A prestação de contas se dá pela entrega do Relatório Anual de Gestão (RAG).

A administração dos recursos do Fundo é de responsabilidade do secretário de saúde 
que deve estar atento às fases da execução orçamentária e ao cumprimento das metas constantes no plano de saúde. Recomenda-se que toda despesa esteja relacionada às metas definidas nos programas estabelecidos no PPA e na LDO, ou poderá configurar-se em um problema. Para gestor e para o SUS, essa é uma situação preocupante considerando a restrição de recurso público, por exemplo (26).

Em virtude da imprevisibilidade das ações judiciais e dos custos delas decorrentes, o trabalho se propõe a identificar quais os impactos da judicialização da saúde no orçamento da Secretaria de Estado de Saúde Distrito Federal no período de 2013 e 2017.

\section{Metodologia}

Trata-se de um estudo descritivo retrospectivo, com utilização da técnica de análise documental com base nos dados de 3.545 processos judiciais contra a Secretaria de Saúde do Distrito Federal (SES-DF), movidos entre 2013 e 2017, requerendo acesso a medicamentos e procedimentos médicos.

As informações foram disponibilizadas pelo Fundo de Saúde do Distrito Federal (FSDF), por intermédio da Diretoria de Análise e Execução Orçamentária (DIOR), em planilha em Excel da Microsoft Office. No banco de dados estavam listados os processos judiciais empenhados no período, conforme solicitado em carta de apresentação da pesquisa e em declaração da UFG.

Ademais, utilizaram-se dados do sistema de informações sobre orçamentos públicos em saúde (SIOPS), de acesso público (http://siops.datasus.gov.br); os relatórios resumidos da execução orçamentária (RREO) gerados a partir do SIOPS - 2013-2017 (30) (31) (32) (33) (34); os fatores de atualização do índice de preços ao consumidor (IPCA) para 2017 (1,304063 (2013), 1,226441 (2014), 1,124867 (2015), 1,034464 (2016) e 1 (2017) (Anexo I), calculados a partir da variação entre as médias anuais do índice divulgado mensalmente pelo Instituto Brasileiro de Geografia e Estatística (IBGE); e os relatórios anual de gestão (RAG) do SES-DF de 2013 a 2016 (35) (36) (37) (38).

Para apresentação da evolução dos gastos com ações judiciais de saúde, os dados quantitativos foram tratados e depois geradas tabelas e gráficos a partir das variáveis: ano (emissão do empenho); programa de trabalho (classificação funcional - no. função e no . subfunção); e valor do empenho de cada processo judicial. Além disso, foi calculada a variação anual dos valores empenhados por ano; o valor médio dos empenhos por ano; a 
participação (\%) dos empenhos por ações judiciais na despesa total com ações e serviços públicos de saúde (ASPS) com recursos próprios por ano; e montante de recursos empenhados segundo subfunção.

O campo intitulado "plano de trabalho" foi lido minuciosamente para extrair os cinco primeiros dígitos do código registrado na planilha e identificar por qual função e subfunções as despesas das ações tinham sido realizadas. Verificou-se que o recurso da saúde (função 10) foi distribuído entre as subfunções: atenção básica (301), assistência hospital e ambulatorial (302), suporte profilático e terapêutico (303), alimentação e nutrição (306) e outros encargos especiais (846).

O campo "especificação" também foi analisado. O objetivo foi conhecer os tipos de demanda por processo judicial que, junto com os dados anteriores, indicaram os efeitos causados pelos gastos com as ações judiciais. Apresentar o fluxo de execução orçamentária da SES-DF, principalmente envolvendo as ações judiciais, foi uma meta não alcançada no trabalho. A pesquisa identificou a ausência de fluxos claros no modus operandi da instituição e existência de uma minuta de procedimento operacional padrão (POP), com redação inacabada, para pedidos de internação em unidade não contratada por esta secretaria (anexo II).

Importante destacar que, somente a partir de 2016, a SES-DF adotou como estratégia uma marcação diferenciada para os processos oriundos da judicialização da saúde. Em uma planilha em Excel, cada registro era marcado como "ação judicial”. Diante disto, é preciso considerar que o número de processos judiciais pode estar subestimado ou superestimado. Sabe-se que o órgão dispõe da plataforma web S-Codes, um sistema de informações que visa controlar e gerenciar demandas judiciais e solicitações administrativas relativas aos serviços de saúde. Contudo, até a finalização dessa pesquisa ainda não estava em funcionamento.

O estudo foi desenvolvido em conformidade com as recomendações éticas.

\section{Resultados e discussão}

\section{Processos judiciais empenhados}

Foram analisados dados de 3.545 processos impetrados contra a Secretária de Saúde do Distrito Federal entre 2013 e 2017. As maiores demandas ocorreram em 2013 e 
2015, 922 (26\%) e 780 (22\%), respectivamente. Em 2016, verificou-se uma grande redução no número de ações judiciais empenhadas, a SES-DF emitiu nota de empenho somente para $471(13,3 \%)$ processos. Essa redução pode ser explicada pela baixa execução orçamentária da assistência farmacêutica em 2016, devido a pagamentos pendentes de outros exercícios financeiros e suspensão de contratos com fornecedores (38).

O montante utilizado para empenhar os processos foi de $R \$ 122,2$ milhões de reais. A maior parcela de recursos foi para 607 processos $(17,1 \%)$ em 2017, $\mathrm{R} \$ 29,2$ milhões de reais $(23,9 \%)$ (tabela 1$)$. O elevado valor de empenho deve-se ao tipo de solicitação, qual seja: aquisição de medicamentos. Desse total, 497 solicitaram a compra de medicamentos.

A execução orçamentária e financeira acontece simultaneamente, uma vez que uma está condicionada a outra. Se há orçamento, mas não há o financeiro disponível, a despesa não pode ser realizada. E, se há financeiro, mas não está previsto no orçamento, o recurso não poderá ser utilizado. O primeiro estágio da despesa é o empenho, momento em que o Estado reconhece a despesa e faz reserva do valor.

Tabela 1: SES/DF - Processos e valores empenhados com ações judiciais por ano. 20132017

\begin{tabular}{ccccc}
\hline Ano & № de Processo empenhados & $\%$ & Valor corrente - R\$ (Milhões) & $\%$ \\
\hline 2013 & 922 & 26 & 18.775 .246 & 15,4 \\
2014 & 765 & 21,6 & 26.307 .316 & 21,5 \\
2015 & 780 & 22 & 28.876 .789 & 23,6 \\
2016 & 471 & 13,3 & 19.060 .195 & 15,6 \\
2017 & 607 & 17,1 & 29.276 .530 & 23,9 \\
Total & 3.545 & 100 & 122.296 .078 & 100 \\
\hline
\end{tabular}

Fonte: FS/DF. Secretaria de Saúde do Distrito Federal. Elaborado pela autora. Nota: Valores correntes, em milhões.

O dispêndio da SES-DF, a valores de 2017, para custear 3.545 ações judiciais no período analisado foi $R \$ 138$ milhões de reais (tabela 2). De 2014 para 2015, houve uma variação positiva de $0,68 \%$, mantendo o custo anual em torno de $R \$ 32$ milhões. De 2016 para 2017, o valor total da despesa aumentou quase que 50\%. Sendo que em 2016 a variação registrada foi negativa, de $-39,30 \%$, e o montante desse ano não ultrapassou a $\mathrm{R} \$ 20$ milhões de reais, o que poderia ser justificado pela baixa execução orçamentária na SES. 
Tabela 2: SES/DF - Variação anual dos valores empenhados com ações judiciais por ano, 2013-2017.

\begin{tabular}{cccr}
\hline Ano & Valor corrente $-\mathrm{R} \$$ (Milhões) & Preços de $2017-\mathrm{R} \$$ (Milhões) & \multicolumn{1}{c}{$\Delta \%$ a.a. } \\
\hline 2013 & 18.775 .246 & 24.484 .104 & \\
2014 & 26.307 .316 & 32.264 .370 & 31,78 \\
2015 & 28.876 .789 & 32.482 .547 & 0,68 \\
2016 & 19.060 .195 & 19.717 .085 & $-39,30$ \\
2017 & 29.276 .530 & 29.276 .530 & 48,48 \\
Total & 122.296 .078 & 138.224 .639 & \\
\hline
\end{tabular}

Fonte: FS/DF. Secretaria de Saúde do Distrito Federal. Elaborado pela autora.

Nota: Preços de 2017 - valores ajustados pelo Índice Nacional de Preços ao Consumidor Amplo (IPCA). Os fatores de correção foram calculados a partir da variação entre as médias anuais do índice divulgado mensalmente pelo IBGE.

Cada processo judicial custou a SES-DF, independente do objeto solicitado pelo usuário, o valor médio de $\mathrm{R} \$ 34$ mil reais. Em 2017 e 2016, cada ação judicial movida custou em média, $\mathrm{R} \$ 40$ mil reais, mais de $15 \%$ se comparado ao valor médio dos cinco anos. Esse montante não retrata o custo real das ações judiciais analisadas. De 607 processos judiciais impetrados (2017), apenas 5 custaram a SES-DF o montante de $\mathrm{R} \$ 7$ milhões de reais. Nesses casos, todos solicitaram aquisição de medicamentos.

Em 2013, a maior despesa foi com a prestação de serviço decorrente da internação de paciente em UTI no valor de $\mathrm{R} \$ 971$ mil reais. Uma ação judicial em 2014 solicitou a compra de medicamento importado custando $R \$ 2$ milhões de reais. $E$, em 2015 e 2016, o valor mínimo da ação judicial foi $R \$ 25$ reais e mais alta $R \$ 1$ milhão de reais. Um processo no valor de $\mathrm{R} \$ 36$ reais solicitava a compra de 'dipropionato de beclometasona', um medicamento essencial encontrado na Relação Nacional de Medicamentos Essenciais (39).

A Lei Complementar $n^{\circ} 141$, de 13 de janeiro de 2012, no seu artigo art. 2o define que despesas com ações e serviços públicos de saúde são "[...] aquelas voltadas para a promoção, proteção e recuperação da saúde que atendam, simultaneamente, aos princípios estatuídos no art. 7ํㅡ da Lei no 8.080, de 19 de setembro de 1990 [...]”. As despesas devem priorizar o acesso universal e igualitário, estar de acordo com as metas elencadas no plano de saúde e ser exclusivamente de responsabilidade da saúde.

O valor total empenhado pela SES-DF com ações judiciais corresponde a $1 \%(R \$ 122$ milhões) da despesa total destinada às ações e serviços públicos de saúde (R\$ 
12.925.041.815 milhões). À primeira vista, o percentual de participação nos recursos previstos para ASPS pode parecer irrelevante. Contudo, se considerando 0 as determinações da LC n 141/2012, da Lei no 8.080/1990 e a Legislação Orçamentária, os processos judiciais movidos contra a SES-DF não deveriam ser empenhados.

Verifica-se nas referidas Leis ausência de matéria específica para processos oriundos da judicialização da saúde. Para que os secretários municipais e estaduais de saúde possam cumprir com as sentenças judiciais, acredita-se que ocorra o remanejamento de recurso ou determinação de abertura de créditos suplementares como solução para a ausência de fonte suficiente. Essas medidas acabam por desconsiderar os princípios do orçamento público, no sentido que ignoram o dito planejamento para cumprir com o direito dos particulares ou coletivos. À vista disso, infere-se que há impactos direto no cumprimento das ações e serviços públicos de saúde em detrimento das ações judiciais.

Do total de reinvindicações judiciais movidas contra a SES-DF entre 2013 e 2017, 2.484 foram empenhadas com $\mathrm{R} \$ 87$ milhões de reais $(71,8 \%)$ da subfunção 303 - suporte profilático e terapêutico. A subfunção indica, do ponto de vista orçamentário, em que área de despesa a ação governamental será realizada (24). A segunda subfunção comprometida foi a 302 - assistência hospitalar e ambulatorial, com $R \$ 34$ milhões de reais $(27,8 \%)$, para 1.021 ações judiciais (tabela 3).

O atendimento ambulatorial e hospitalar pelo SUS são serviços oferecidos em estabelecimentos de administração municipal, estadual, federal e filantrópica. Enquanto o suporte profilático e terapêutico tem relação com a disseminação e contaminação educação sanitária, identificação e tratamento dos doentes assintomáticos (40).

Tabela 3: Recursos empenhados com ações judiciais segundo Subfunção, 2013-2017

\begin{tabular}{lcrr}
\hline Subfunções & $\begin{array}{c}\text { No processos } \\
\text { Empenhados }\end{array}$ & Valor - (R\$ Milhões) & \multicolumn{1}{c}{$\%$} \\
\hline 301 - Atenção Básica & 1 & 15.560 & 0,01 \\
302 - Assistência Hospitalar e Ambulatorial & 1.021 & 34.068 .626 & 27,86 \\
303 - Suporte profilático e terapêutico & 2.484 & 87.843 .961 & 71,83 \\
306 - Alimentação e Nutrição & 7 & 124.040 & 0,10 \\
846 - Outros encargos especiais & 15 & 243.888 & 0,20 \\
Total & & 122.296 .078 & 100,00 \\
\hline
\end{tabular}

Fonte: FS/DF. Secretaria de Saúde do Distrito Federal. Elaborado pela autora.

Nota: Valores correntes, em milhões. 
Nos últimos anos, o número de ações judiciais impetradas no Judiciário para ter acesso à medicamentos, diagnósticos e serviços de saúde aumentou consideravelmente. Considerando que a judicialização da saúde não é um acontecimento recente e cada ano elevam-se os custos para cumprimento das sentenças dos juízes, infere-se que já teria sido estabelecido formalmente no orçamento público dispositivos, subfunção ou classificação da despesa de natureza específica, por exemplo, para processos judicializados. Contudo, isso ainda não ocorreu. De acordo com a documentação que o estudo teve acesso, verificou-se que na estrutura da programação orçamentária não há nada explícito a respeito da judicialização da saúde, tampouco na estrutura do Fundo de Saúde do Distrito Federal.

Medicamentos; internação compulsória; órteses e próteses; exames e procedimentos; UTI; matéria médico-hospitalar; fórmulas nutricionais e Home Care foram as reinvindicações dos usuários. Foram empenhados 2.498 processos judiciais (70,5\%) relacionados ao fornecimento de medicamentos pelo SUS; 372 ações judiciais (10,5\%) reivindicando a prestação de serviços de internação compulsória; 271 ações judiciais pedindo órteses e próteses (7,6\%) e 157 ações judiciais requerendo exames e procedimentos (4,4\%) (gráfico 1$)$.

De Oliveira e Silveira (41) assinalam que os medicamentos mais solicitados em ações judiciais são os impostos pelo SUS, medicamentos de alto custo, medicamentos off label e medicamentos com eficácia questionável, com destaque para o tratamento das doenças crônicas, como câncer, hepatites, diabetes e doenças raras. Destacam, ainda, que o governo brasileiro não motiva fabricantes locais que produzem medicamentos considerados "órfãos" destinados à pacientes portadores de doenças raras como, por exemplo, doença de Fabry.

Gráfico 1: Ações judiciais empenhadas por objeto do processo segundo ano, 2013-2017

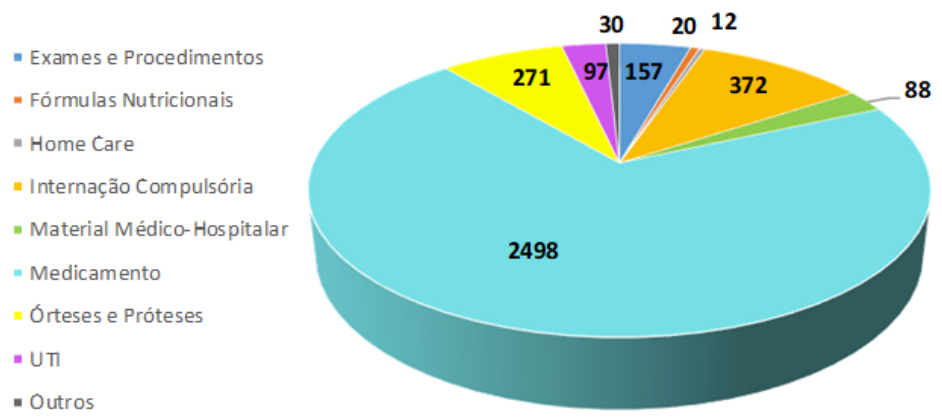

Fonte: FS/DF. Secretaria de Saúde do Distrito Federal. Elaborado pela autora. 


\section{Efeito orçamentário da judicialização}

A maior concentração de ações judiciais foi para aquisição de medicamentos (1.618) e prestação de serviços de exames e procedimentos no triênio 2013-2015 (gráfico 2). Internação compulsória apesar de ter acumulado maior número de processos judiciais em cinco anos (372), depois de medicamentos, nota-se que o ano com maior demanda por parte dos usuários foi em 2014, com 114 (14,9\%). A solicitação por órteses e próteses foi mais intensa em 2014, com 135 (17,6\%) ações judiciais. Os dados apontam que pedidos referentes à prestação de serviços com UTI ocorreu em 2013, 97 ações judiciais (10,5\%).

Gráfico 2: Ações judiciais por objeto e ano de empenho, 2013-2017.

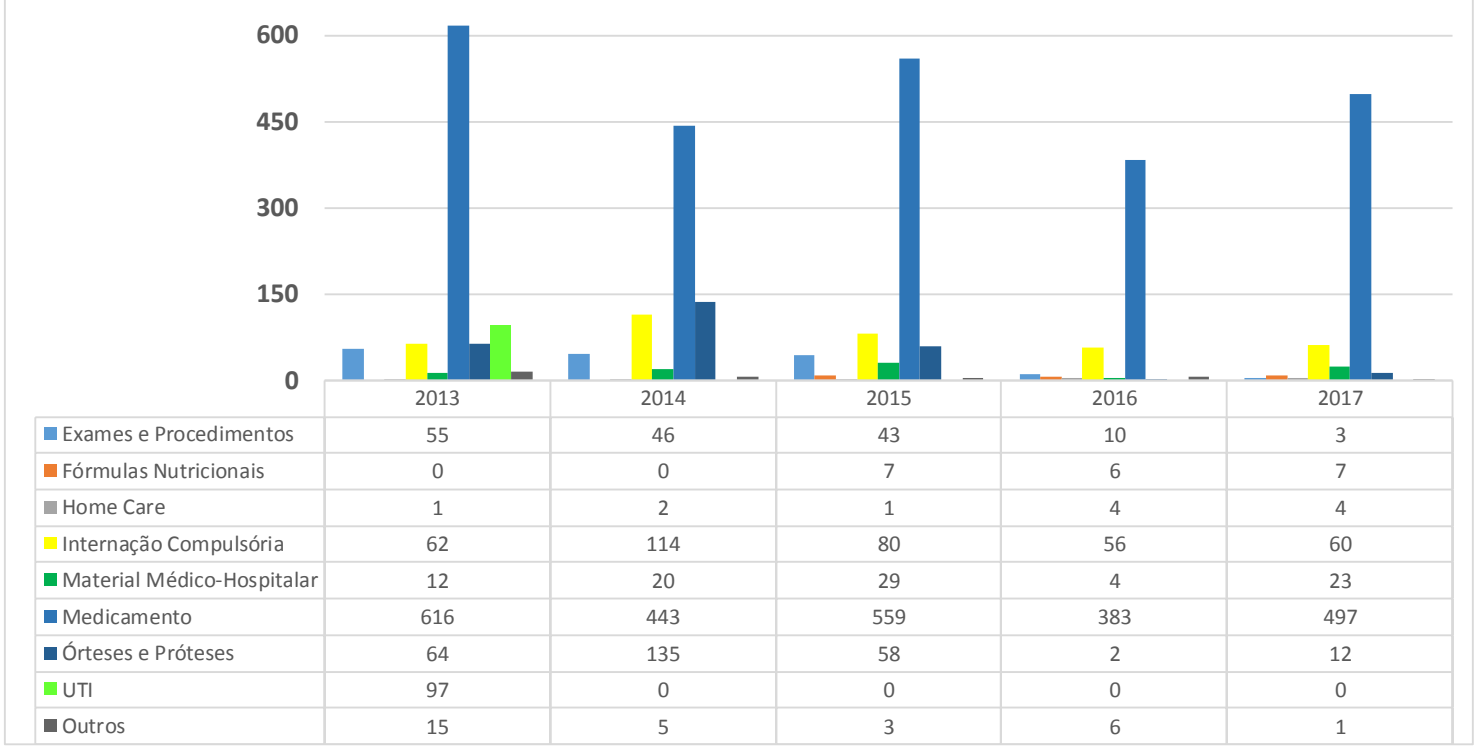

Fonte: FS/DF. Secretaria de Saúde do Distrito Federal. Elaborado pela autora.

O volume de recurso empenhado para aquisição de órteses e próteses foi elevado, $\mathrm{R} \$ 9,5$ milhões de reais $(7,8 \%)$, para a baixa quantidade de processos registrados (tabela 4). Em primeiro e segundo lugar com maior volume de recurso orçamentário, assim como em números absolutos de reinvindicações judiciais, ficou a aquisição de medicamentos e a prestação de serviços de internação compulsória, $R \$ 88$ milhões de reis $(72,2 \%)$ e 17 milhões de reais $(14,5 \%)$. Analisando ano a ano, constata-se que o montante dispendido para esses dois objetos se manteve alto durante todo o período.

Consoante o artigo 9o, da Lei ํo 10.2016, de abril de 2001 (42), a internação compulsória é estipulada pelo juiz competente, "que levará em conta as condições de 
segurança do estabelecimento, quanto à salvaguarda do paciente, dos demais internados e funcionários". Na mesma lei, no artigo $6^{\circ}$, diz que a internação psiquiátrica acontecerá por laudo médico circunstanciado que caracterize a real necessidade desta. Infere-se assim que a articulação entre os saberes médicos e jurídicos deve existir para chegar a um consenso a respeito de uma intervenção.

Tabela 4: Recursos empenhados (\%) com ações judiciais segundo objeto, 2013-2017

\begin{tabular}{|c|c|c|c|c|c|c|c|c|c|c|}
\hline \multirow{2}{*}{$\begin{array}{l}\text { Objeto do } \\
\text { processo }\end{array}$} & \multicolumn{2}{|c|}{2013} & \multicolumn{2}{|c|}{2014} & \multicolumn{2}{|c|}{2015} & \multicolumn{2}{|c|}{2016} & \multicolumn{2}{|l|}{2017} \\
\hline & $\begin{array}{c}\mathrm{R} \$ \\
\text { (Milhões) }\end{array}$ & $\%$ & $\begin{array}{c}\mathrm{R} \$ \\
\text { (Milhões) }\end{array}$ & $\%$ & $\begin{array}{c}\mathrm{R} \$ \\
\text { (Milhões) }\end{array}$ & $\%$ & $\begin{array}{c}\mathrm{R} \$ \\
\text { (Milhões) }\end{array}$ & $\%$ & $\begin{array}{c}\mathrm{R} \$ \\
\text { (Milhões) }\end{array}$ & $\%$ \\
\hline $\begin{array}{l}\text { Exames e } \\
\text { Procedimentos }\end{array}$ & 773 & $\%$ & 229 & $\%$ & 165 & 0,6 & 31 & 0,2 & 7 & 0,0 \\
\hline $\begin{array}{l}\text { Fórmulas } \\
\text { Nutricionais }\end{array}$ & - & 4,1 & - & 0,9 & 90 & 0,3 & 34 & 0,2 & 52 & 0,2 \\
\hline Home Care & 33 & 0,0 & 110 & 0,0 & 193 & 0,7 & 910 & 4,8 & 252 & 0,9 \\
\hline $\begin{array}{l}\text { Internação } \\
\text { Compulsória }\end{array}$ & 2.125 & 0,2 & 5.902 & 0,4 & 4.415 & 15,3 & 2.812 & 14,8 & 2.506 & 8,6 \\
\hline $\begin{array}{l}\text { Material } \\
\text { Médico- } \\
\text { Hospitalar }\end{array}$ & 278 & 11,3 & 2280 & 22,4 & 112 & 0,4 & 68 & 0,4 & 668 & 2,3 \\
\hline Medicamento & 11.376 & 1,5 & 15.988 & 0,9 & 20.343 & 70,5 & 15.064 & 79,0 & 25.498 & 87,1 \\
\hline $\begin{array}{l}\text { Órteses e } \\
\text { Próteses }\end{array}$ & 1.976 & 60,6 & 3.738 & 60,8 & 3.523 & 12,2 & 40 & 0,2 & 288 & 1,0 \\
\hline UTI & 2.115 & 10,5 & - & 14,2 & - & 0,0 & - & 0,0 & - & 0,0 \\
\hline Outros & 96 & 11,3 & 108 & 0,0 & 32 & 0,1 & 96 & 0,5 & 1 & 0,0 \\
\hline Total & 18.775 & 0,5 & 26.307 & 0,4 & 28.876 & 100,0 & 19.060 & 100,0 & 29.276 & 100 \\
\hline
\end{tabular}

Fonte: FS/DF. Secretaria de Saúde do Distrito Federal. Elaborado pela autora.

Nota: Valores correntes, em milhões.

A SES-DF hoje trabalha com ações de fornecimento, que são aquisições de materiais específicos. O processo é feito por dispensa de licitação (DL), que começa com o fornecimento não culminando em um contrato. Neste caso, a nota de empenho tem força de contrato como prevê o artigo 62, da Lei №. 8.666/1993 (43). O grande volume de aquisição na secretaria é com materiais e medicamentos oncológicos. No caso da prestação de serviços com UTI, a secretaria trabalha com contrato de serviço. Até 2016, material ou medicamento solicitado que custasse até $R \$ 8$ mil reais era adquirido por meio do programa de atendimento às demandas judiciais em saúde (PAD-JUD). Esse é regulamentado pela Portaria № 223, de 24 de novembro de 2011.

A aquisição de medicamentos foi objeto de processo judicial mais demandado na 
judicialização da saúde. Essa constatação também é frequente em outros estudos realizados pelo país. A exemplo, em um seminário realizado em Brasília sobre a judicialização da política pública de saúde, Siqueira (2018) apresentou que em dezembro de 2016, em São Paulo, havia aproximadamente 51 mil ações judiciais em atendimento, sendo $58 \%$ de prescrição médica particular, 65\% solicitavam o fornecimento de medicamentos, $78 \%$ dos medicamentos não eram padronizados pelo SUS, $22 \%$ indicava marca comercial específica, dentre outros.

De acordo com os relatórios de gestão da secretaria - documento que apresenta o desenvolvimento das ações previstas e resultados alcançados com a execução da PAS, entre 2013-2016 foi empenhado em favor das ações de assistência farmacêutica o montante de $R \$ 759$ milhões de reais e deste, $R \$ 62$ milhões foi utilizado com ações judiciais $(8.21 \%)$.

O ano de 2014 chamou atenção. As ações judiciais comprometeram 9,85\% (R\$ 15 milhões de reais) do total de recurso previsto para despesas com assistência farmacêutica. Ademais, esse ano foi marcado por um desabastecimento farmacêutico explicado por falha na programação de medicamentos e insumos, licitações desertas, descontinuidade pelo fornecedor, dentre outros. Configurou-se um cenário preocupante não apenas para o órgão, como para a população que depende do sistema de saúde. Pode-se inferir assim que o órgão apresentava sérias deficiências no processo de planejamento institucional naquele ano, e possivelmente nos anteriores.

A RAG de 2014 mostrou que o gasto com medicamentos foi $13 \%$ acima do valor previsto para aquele ano ( $\mathrm{R} \$ 160$ milhões) (36). Com esse montante, a SES-DF adquiriu aproximadamente 17.000.000 unidades dos componentes básicos e 15.000.000 unidades de componentes especializados. O Componente básico da assistência farmacêutica destina-se ao fornecimento dos medicamentos e insumos para o tratamento de diabetes, programa de hipertensão arterial, saúde da mulher, fitoterapia, saúde mental e bexiga neurogênica; e o componente especializado compreende as linhas de cuidado definidas em protocolos clínicos e diretrizes terapêuticas (PCDT) (40). 
Tabela 5 - Empenhos da judicialização com assistência farmacêutica versus empenhos da SES - DF com assistência farmacêutica, 2013-2017

\begin{tabular}{cccc}
\hline Ano & $\begin{array}{c}\text { Judicialização } \\
\text { (R\$ Milhões) }\end{array}$ & $\begin{array}{c}\text { Despesas empenhadas c/ ass. Farmacêutica* } \\
\text { (R\$ Milhões) }\end{array}$ & $\%$ \\
\hline 2013 & $\mathrm{R} \$ 11.308 .349$ & $\mathrm{R} \$ 151.542 .712$ & $7,46 \%$ \\
2014 & $\mathrm{R} \$ 15.811 .393$ & $\mathrm{R} \$ 160.469 .570$ & $9,85 \%$ \\
2015 & $\mathrm{R} \$ 20.153 .617$ & $\mathrm{R} \$ 234.210 .045$ & $8,60 \%$ \\
2016 & $\mathrm{R} \$ 15.080 .362$ & $\mathrm{R} \$ 213.105 .024$ & $7,08 \%$ \\
Total & $\mathrm{R} \$ 62.353 .721$ & $\mathrm{R} \$ 759.327 .352$ & $8,21 \%$ \\
\hline
\end{tabular}

Fonte: Elaboração da autora

* Extraído dos RAG disponíveis no sítio http://www.saude.df.gov.br/relatorio-anual-de-gestao-rag/

** o RAG de 2017 não foi disponibilizado.

No exercício seguinte, em 2015, as dificuldades gerenciais e econômicas enfrentadas pela SES-DF continuaram (37). O orçamento da assistência farmacêutica não seguiu uma programação de aquisição, pois não havia um mapeamento adequado sobre insumos e medicamentos dos diferentes equipamentos de saúde da SES-DF, ocorrendo assim a descontinuidade do fornecimento de materiais e medicamentos diversos. Esses acontecimentos corroboram para o aumento da judicialização da saúde e, por consequência, para outros embaraços na instituição além dos que já estavam instalados.

Do recurso da assistência farmacêutica, $8,21 \%$ foi empenhado com processos judiciais solicitando a aquisição de medicamentos nacional e importado (tabela 5). Sobre o comportamento de 2017, não foi possível comentar tendo em vista que o RAG ainda não estava disponível no sítio da SES-DF.

\section{Considerações finais}

O número de ações judiciais impetradas no Judiciário para ter acesso à medicamentos, diagnósticos e serviços de saúde aumentou consideravelmente no período analisado. A aquisição de medicamentos foi objeto de processo judicial mais demandado na judicialização da saúde e comprometeu quase $9 \%$ do recurso da assistência farmacêutica no período analisado.

A judicialização apesar de ser um instrumento importante de garantia dos direitos dos cidadãos, ou de reafirmação da cidadania, apresenta alguns aspectos que causam profundas distorções no funcionamento do sistema de saúde brasileira e mais particularmente no Distrito Federal. Além de reforçar a iniquidade, provoca dificuldades na 
operação cotidiana das equipes que fazem a gestão do sistema de saúde. Dificuldades essas distribuídas pelas áreas administrativas (compras, almoxarifado, distribuição), financeiras (execução orçamentaria, pagamentos), assistência farmacêutica, atenção à saúde, e constantemente para o próprio gestor estadual.

A judicialização da saúde contribui e tem efeito negativo na execução orçamentária da secretaria, inviabilizando em parte o cumprimento de ações e serviços de saúde previstas no Plano de Saúde além de impossibilitar uma eficiente aplicação dos recursos. A SES-DF acumulou dificuldades de ordem gerencial, orçamentária e financeira, de recursos humanos e materiais de exercícios anteriores, que se agravam cada vez mais.

Destaca-se que a estrutura do orçamento federal e o modus operandi da secretaria hoje não oferecem instrumentos capazes para acompanhar, controlar e avaliar gastos de forma efetiva das ações judiciais. Considerando que a judicialização da saúde não é um acontecimento recente e cada ano elevam-se os custos para cumprimento das sentenças dos juízes, infere-se que já teria sido estabelecido formalmente no orçamento público dispositivos, subfunção ou classificação da despesa de natureza específica para processos judicializados. Na SES-DF, a ausência de uma equipe e/ou departamento exclusivo para a tramitação completa de demandas judiciais contribui para a continuidade do cenário complexo

\section{Referências}

1. Chieffi AL, Siqueira PSF. Judicialização da Saúde no Estado de São Paulo. In: Judicialização da Saúde no Brasil. (org.). Lenir Santos, Fernanda Terrazas. Campinas: Saberes Editora, 2014.

2. Barroso LR. Da falta de efetividade à judicialização excessiva: direito à saúde, fornecimento gratuito de medicamentos e parâmetro para a atuação judicial. In: Neto CS, Sarmento D. (org.) Direitos Sociais: fundamentos, judicialização e direitos sociais em espécie. Rio de Janeiro: Lumem Juris, 2010.

3. Mendes A. A busca da cumplicidade entre o planejamento e o processo orçamentário na Saúde Paulistana. In: Mendes A, Souza MF (org.). Tempos Radicais da Saúde em São Paulo: A construção do SUS na Maior Cidade Brasileira. São Paulo: Hucitec, 2003.

4. Brasil. Constituição (1988). Constituição da República Federativa do Brasil. Disponível em: http://www.planalto.gov.br/ccivil_03/constituicao/constituicaocompilado.htm Acesso em 15.12.2017 
5. Mendes A, Marques RM. Sobre a economia da saúde: campos de avanço e sua contribuição para a gestão da saúde pública no Brasil. In: Campos GWS et al. (orgs). Tratado de saúde coletiva. São Paulo: Hucitec, 2012.

Disponível em: http://www.planalto.gov.br/ccivil_03/leis/LCP/Lcp141.htm. Acesso em 15.12.2017

6. Vieira FS, Zucchi P. Distorções causadas pelas ações judiciais à política de medicamentos no Brasil. Rev. Saúde Pública, 2007, 41(2):214-222. Disponível em: http://www.scielo.br/scielo.php?pid=S0034-

$9102007000200007 \&$ script=sci_abstract\&tlng=pt. Acesso em 15.12.2017.

7. Romero LC. Judicialização das Políticas de Assistência Farmacêutica: o caso do Distrito Federal. Brasília: Ipea, 2008. Disponível em:

https://www12.senado.leg.br/publicacoes/estudos-legislativos/tipos-de-estudos/textos-paradiscussao/td-41-judicializacao-das-politicas-de-assistencia-farmaceutica-o-caso-do-distritofederal. Acesso em 10.1.2018.

8. Diniz D, Medeiros M, Schwartz IVD. Consequências da judicialização das políticas de saúde: custos de medicamentos para as mucopolissacaridoses. Cad. Saúde Pública, 2012, 28(3):479-489. Disponível em:

http://www.scielo.br/scielo.php?script=sci_arttext\&pid=S0102-311X2012000300008.

Acesso em 10.1. 2018.

9. Tribunal de Contas da União Notícias. Aumentam os gastos públicos com judicialização da saúde. Brasília, 23.8.2017. Disponível em:

http://portal.tcu.gov.br/imprensa/noticias/aumentam-os-gastos-publicos-com-judicializacaoda-saude.htm. Acesso em 20 dez.2017

10. Andrade EIG et al. A judicialização da saúde e a política nacional de assistência farmacêutica no Brasil: gestão da clínica e medicalização da justiça. CEP, 2008, 30130:100.

11. Dallari SG. Aspectos particulares da chamada judicialização da saúde. Revista de Direito e Sanitário, 2013, 14(1): 77-81. Disponível em:

http://www.revistas.usp.br/rdisan/article/view/56624/59641Acesso em 3 jan 2018 Acesso em: 2.3.2018

12. Ministério da Saúde. Política nacional de medicamentos 2001. Disponível em: http://bvsms.saude.gov.br/bvs/publicacoes/politica_medicamentos.pdf. Acesso em 15 mar2018

13. Management Sciences For Health (MSH). Managing Drug Supply: the selection, procurement, distribuction and use of pharmaceuticals. West Hartford: Management Sciences for Health; World Health Organization (Col.): Kumarion Press, 1997.

14. Delduque MC, Marques SB. A Judicialização da política de assistência farmacêutica no Distrito Federal: diálogos entre a política e o direito. Revista Tempus Actas de Saúde Coletiva, 2011, 5(4): 97-106. Disponível em: 
http://www.tempusactas.unb.br/index.php/tempus/article/view/1060/968 Acesso em 2.2.2018.

15. Biehl J, Petryna A. Tratamentos jurídicos: os mercados terapêuticos e a judicialização do direito à saúde. História, Ciências, Saúde-Manguinhos, 2016, 23(1):173-192.

16. Neto $C$ et al. Médicos, advogados e indústria farmacêutica na judicialização da saúde em Minas Gerais, Brasil. Revista de Saúde Pública, 2012, 46:784-790.

17. Sartori Junior D et al. Judicialização do acesso ao tratamento de doenças genéticas raras: a doença de Fabry no Rio Grande do Sul. Ciênc. Saúde coletiva [online]. 2012, 17(10):2717-2728. Disponível em: http://www.scielo.br/scielo.php?pid=S1413$81232012001000020 \&$ script=sci abstract\&tlng=pt Acesso em 2.2.2018.

18. Ferraz OLM, Vieira FS. Direito à saúde, recursos escassos e equidade: os riscos da interpretação judicial dominante. Dados, 2009, 52(1):223-5.

19. Ramos RS, Gomes AMT. A judicialização da saúde pública no brasil: um estudo de representações sociais. Revista Cuidarte, 2014, 5(2):827-836.

20. Trevisan LM et al. Access to treatment for phenylketonuria by judicial means in Rio Grande do Sul, Brazil. Ciencia \& saude coletiva, 2015, 20(5):1607-1616.

21. Secretaria do Tesouro Nacional, 2018. Execução Orçamentária. Disponível em: http://www.tesouro.fazenda.gov.br/-/execucaoorcamentaria?redirect=http $\% 3 \mathrm{~A} \% 2 \mathrm{~F} \% 2 \mathrm{Fwww}$. tesouro.fazenda.gov.br\%2Fhome $\% 3 \mathrm{Fp} p$ id \%3D3\%26p p lifecycle\%3D0\%26p p state\%3Dmaximized\%26p p mode\%3Dview\%26 3 keywords\%3Dor\%25C3\%25A7amento\%26 3 struts action\%3D\%252Fsearch\%252Fsear ch\%26 3 redirect\%3D\%252F Acesso em 25.1.2018.

22. Albuquerque CM. Gestão de finanças públicas. In: Albuquerque $C M$, Medeiros MB, Silva PHF. Brasília: Editora Gestão Pública, 2008.

23. Brasil. Portaria no 42, de 14 de abril de 1999. Atualiza a discriminação da despesa por funções de que tratam 0 inciso I do $\S 10$ do art. 20 e $\S 20$ do art. 80, ambos da Lei no 4.320, de 17 de março de 1964, estabelece os conceitos de função, subfunção, programa, projeto, atividade, operações especiais, e dá outras providências. Disponível em: http://www.planejamento.gov.br/assuntos/orcamento-1/legislacao/legislacao/portaria-mog42_1999_atualizada_23jul2012-1.doc/view

Acesso em 10.1.2018.

24. Ministério do Planejamento, Desenvolvimento e Gestão. Manual Técnico de Orçamento - MTO, 2018. Disponível em:

http://www.planejamento.gov.br/assuntos/orcamento-1/informacoesorcamentarias/arquivos/MTOs/mto atual.pdf/view Acesso em 2.2.2018

25. BRASIL. Lei no 4.320, de 17 de março de 1964. Estatui Normas Gerais de Direito 
Financeiro para elaboração e contrôle dos orçamentos e balanços da União, dos Estados, dos Municípios e do Distrito Federal. Disponível em:

http://www.planalto.gov.br/ccivil 03/Leis/14320.htm Acesso em 4 dez 2017

26. Mendes AN. Financiamento, gasto e gestão do Sistema Único de Saúde (SUS): a gestão descentralizada semiplena e plena do sistema municipal no Estado de São Paulo (1995-2001). Programa de Pós-graduação em Economia: Universidade Estadual de Campinas. Campinas, 2005. Disponível em:

http://www.bibliotecadigital.unicamp.br/document/?code=vtls000376445\&opt=1 .

Acesso em 15.12.2017.

27. Brasil. Lei no 8.080, de 19 de setembro de 1990. Dispõe sobre as condições para a promoção, proteção e recuperação da saúde, a organização e o funcionamento dos serviços correspondentes e dá outras providências. Disponível em:

http://www.planalto.gov.br/ccivil_03/leis//8080.htm Acesso em 2.2.2018.

28. Brasil. Lei no 8.142, de 28 de dezembro de 1990. Dispõe sobre a participação da comunidade na gestão do Sistema Único de Saúde (SUS\} e sobre as transferências intergovernamentais de recursos financeiros na área da saúde e dá outras providências. Disponível em http://conselho.saude.gov.br/legislacao/lei8142_281290.htm Acesso em 2.2.2018.

29. Brasil. Lei complementar ํㅜ 141, de 13 de janeiro de 2012. Regulamenta o § 30 do art. 198 da Constituição Federal para dispor sobre os valores mínimos a serem aplicados anualmente pela União, Estados, Distrito Federal e Municípios em ações e serviços públicos de saúde [...] e dá outras providências. Disponível em: http://www.planalto.gov.br/ccivil 03/Leis/LCP/Lcp141.htm Acesso em 2.2.2018.

30. Ministério da saúde. DATASUS. Relatório resumido da execução orçamentária (RREO) - Demonstrativo da receita de impostos líquida e das despesas próprias com ações e serviços públicos de saúde orçamentos fiscal e da seguridade social: Exercício de 2013. Disponível em: http://siops.datasus.gov.br/rel LRFUF.php Acesso em 25.12.2017.

31. Ministério da saúde. DATASUS. Relatório resumido da execução orçamentária (RREO) - Demonstrativo da receita de impostos líquida e das despesas próprias com ações e serviços públicos de saúde orçamentos fiscal e da seguridade social: Exercício de 2014. Disponível em: http://siops.datasus.gov.br/rel_LRFUF.php Acesso em 15.3.2018.

32. Ministério da saúde. DATASUS. Relatório resumido da execução orçamentária (RREO) - Demonstrativo da receita de impostos líquida e das despesas próprias com ações e serviços públicos de saúde orçamentos fiscal e da seguridade social: Exercício de 2015. Disponível em: http://siops.datasus.gov.br/rel_LRFUF.php Acesso em 25.12.2017.

33. Ministério da saúde. DATASUS. Relatório resumido da execução orçamentária (RREO) - Demonstrativo da receita de impostos líquida e das despesas próprias com ações e serviços públicos de saúde orçamentos fiscal e da seguridade social: Exercício de 2016. Disponível em: http://siops.datasus.gov.br/rel_LRFUF.php Acesso 2.2.2018. 
34. Ministério da saúde. DATASUS. Relatório resumido da execução orçamentária (RREO)

- Demonstrativo da receita de impostos líquida e das despesas próprias com ações e serviços públicos de saúde orçamentos fiscal e da seguridade social: Exercício de 2017. Disponível em: http://siops.datasus.gov.br/rel_LRFUF.php Acesso em 15.1.2018.

35. Secretaria de Estado de Saúde. Relatório anual de gestão: 2013. Disponível em: http://www.saude.df.gov.br/wp-conteudo/uploads/2017/11/RAG 2013 PARTE I.pdf Acesso em 18.1.2018.

36. Secretaria de Estado de Saúde. Relatório anual de gestão: 2014. Disponível em: http://www.saude.df.gov.br/wp-conteudo/uploads/2017/11/RAG_2014_Versao_Final.pdf Acesso em 2.2.2018.

37. Secretaria de Estado de Saúde. Relatório anual de gestão: 2015. Disponível em: http://www.saude.df.gov.br/wp-conteudo/uploads/2017/11/RAG_2015_SESDF.pdf Acesso 15.1.2018.

38. Secretaria de Estado de Saúde. Relatório anual de gestão: 2016. Disponível em: http://www.saude.df.gov.br/wp-conteudo/uploads/2017/11/RAG-2016-Parte-I.pdf Acesso em 2.2.2018.

39. Ministério da Saúde. Relação Nacional de Medicamentos Essenciais: RENAME 2017. Disponível em:

http://bvsms.saude.gov.br/bvs/publicacoes/relacao nacional medicamentos rename 2017 .pdf Acesso em 4.12.2017.

40. Ministério da Saúde. Componente Básico da Assistência Farmacêutica (CBAF). Disponível em: http://portalms.saude.gov.br/assistencia-farmaceutica/medicamentosrename/componente-basico-da-assistencia-farmaceutica-cbaf Acesso em 3.3.2018.

41. De Oliveira AG, Silveira D. Medicamentos órfãos-doenças raras e a judicialização da saúde. Infarma-Ciências Farmacêuticas, 2016, 27(4):203-204.

42. BRASIL. Lei no 10.2106, de 6 abril de 2001. Dispõe sobre a proteção e os direitos das pessoas portadoras de transtornos mentais e redireciona o modelo assistencial em saúde mental. Disponível em:

http://www.planalto.gov.br/ccivil_03/leis//8666cons.htm Acesso em 4.12.2017.

43. Brasil. Lei no 8.666, de 21 de junho de 1993. Regulamenta o art. 37, inciso XXI, da Constituição Federal, institui normas para licitações e contratos da Administração Pública e dá outras providências. Disponível em:

http://www.planalto.gov.br/ccivil_03/leis//8666cons.htm Acesso em 4.12.2017 
Recebido em: 5.6 .2018

Aprovado em: 18.6.2018

\section{Como citar este artigo:}

Chagas CP, Santos FP. Efeitos do gasto com a judicialização da saúde no orçamento da Secretaria Estadual de Saúde do Distrito Federal entre 2013 e 2017. Revista Cadernos Ibero-Americanos de Direito Sanitário. 2018 abr./jun, 7(2):147-172. 